\title{
Effect of Particle Size Distribution on Ammonium Sulphate Dried in a Rotary Dryer
}

\author{
Susianto ${ }^{1}$, Ali Altway ${ }^{1}$, Kuswandi ${ }^{1}$, and Margono ${ }^{1}$
}

\begin{abstract}
The aim of this work is to study theoretically, by mathematical model development, the effect of particle size distribution on the performance of rotary dryer to dry ammonium sulphate fertilizer assuming plug flow with axial dispersion pattern (PFDA model) for solid particle flow. The mathematical model development was carried out by combining the drying processes model with particle size distribution model. Particle size distribution models used are Rosin-Rommler model and Gamma distribution model. For simplicity, the model of drying processes of solid particles in the rotary dryer was developed by assuming of uniform air conditions (temperature and humidity) along the rotary dryer as in the entry conditions. The resulting differential equations were solved analytically under Matlab 6.1 facility.Since this model, solid hold up, and axial dispersion number were obtained from empirical correlations in the literatures. The drying rate of ammonium sulphate fertilizer in rotary dryer was estimated using isothermal diffusion model with effective diffusivity of moisture in the particle obtained from previous study [2]. Using Gamma function distribution, this research showed that for the value of the coefficient of variance $(\mathrm{CV})$ less than 0.5, particle size distribution does not have significant effect on dryer performance. For the value of $\mathrm{CV}$ greater than 0.5 , the dryer performance increase (or outlet solid moisture content decrease) with increasing the value of $\mathrm{CV}$. The application of Rosin-Rammler model gives lower prediction of outlet solid moisture content compared to the application of Gamma function model.
\end{abstract}

Keywords-Particle size distribution, coefficient of variation, moisture content, analytical solution

\section{INTRODUCTION}

$\mathrm{D}$ rying which occurs in the rotary dryer is a process that has long been used in industry. For example, the fertilizer industry uses a rotary dryer to dry ammonium sulphate (ZA), superphosphate, and NPK. Rotary dryer is an equipment commonly used in the drying process of material that is not easily broken and not sensitive to heat. Fundamental events that include simultaneous transfer of heat from the drying medium (usually air) to the solid and the mass transfer of water from the solids to the drying medium occurred during the drying process in the RD [22]. The process occuring in rotary dryer is very complex and still less well understood. Describe drying process in rotary dryer is described by Fuzzy modeling $[16,23]$.

To enhance the effectiveness of contact between solid and gas, the rotary dryer is equipped with flights, which are placed along the cylinder. Volume of materials transported by the flights is between 10 to $15 \%$ of the total volume of material contained in a rotary dryer [15]. The mechanism is as follows, as the dryer rotates solid

${ }^{1}$ Susianto, Ali Altway, Kuswandi, and Margono are with Department of Chemical Engineering, FTI, Institut Teknologi Sepuluh Nopember, Surabaya, 60111, Indonesia. E-mail: alimohad@chem-eng.its.ac.id, alimohay@yahoo.com. is taken up by the flights, up to a certain distance and then the solid is poured over the air. Most of the drying occurs at this time, where the solid contacts with the gas. Flights also serves to transport the solid through the cylinder [25].

To be able to analyze and design a rotary dryer properly, the information concerning heat transfer, mass transfer, and solid transport in rotary dryer is needed. This has been explored by previous researchers experimentally, as Friedman \& Marshall [5] who developed the research to find a correlation of volumetric heat transfer coefficient in rotary dryer. Friedman and Marshall [5] conducted a research to estimate the amount of solidmaterial resides in a dryer that affect the heat transfer rate. Hold up correlations have been obtained both for cocurrent flow or counter-current. Friedman and Marshall [6] conduct research on the influence of air speed, feed rate, rotation speed, slope, and the number of flight on heat transfer rate that occurs in the rotary dryer. Research on solid hold up or the average residence time of solid in a rotary dryer has been carried out by Pan et al[18], Purutyan et al [20], Kemp [12]. Kemp [12] examined the particle motion in cascade rotary dryers and he obtained a new formula to replace the existing formula and this formula is used for early design. Pan et al (2006), have created a model for the granule transport based on motion analysis and have obtained a method for calculating the mean residence time of granule. Theoretical studies are needed to predict rotary dryer performance based on heat and mass transfer process and solid transport mechanisme.

The drying process is influenced both by external conditions, such as temperature, velocity, humidity of drying air and particle size distribution and by internal drying mechanism inside the solid which depends on the solid particle characteristic including pore structure, hygroscopic characteristic, shape and size of the particles. A number of theories (models) that describe the process of drying of solid particles has been developed by previous researchers such as Akpinar and Dincer [1], Haghi and Angiz [8], Haghi [9, 10]. These researchers estimate theoretically the rate of drying with the diffusion model. Meanwhile, theoretical studies for the performance of the drying process in the rotary dryer (for some specific materials) has been developed by several researchers, including the Yliniemi [25] uses the assumption of uniform particle size and makes the flow of solid particles in a rotary dryer a mixed flow (lump-parameter model); and Wang et al [24], Kiranoudis et al [13], Pacheco \& Stella [19], Menshutina et al [17] which also used the uniform particle size assumption but the solid and gas flow inside the rotary dryer is assumed plugflow (distributed parameter model).

Fernandes et al [4] and Schofield and Glikin [21] studied the mathematical modeling of industrial fertilizer rotary dryer using uniform particle size and plug flow of 
solid assumption.In industrial dryer, the particle size is generally not uniform and when the solids in the rotary dryer was taken up by the flight at a certain height and then dropped into the bottom of the rotary dryer, back mixing occurs in solid flow, so that the solid and gas flow characteristics are non-ideal in the real process (not a plugflow or mixed flow). Besides, the previous researchers assumed uniform particle size in their mathematical model development.

This study aims to examine theoretically (by mathematical model development) the influence of particle size distribution on rotary dryer performance by considering solid backmixing. Rosin-Rammler and gamma funtion modeling were used to describe particle size distribution.

\section{METHOD}

This study was carried out experimentally and theoretically to study drying process of ammonium sulphate fertilizer in rotary dryer. The rotary dryer system under study is that used in PT. Petrokimia Gresik. The dryer is cylindrical shaped with a diameter of $2.418 \mathrm{~m}$ and a length of $12.2 \mathrm{~m}$. The rotary dryer is placed with the slope of $4.5 \%$ and the cylinder rotated at $3.5 \mathrm{rpm}$. The inside of the cylinder is equipped with 20 flight. Hot air was used as the drying media. The rotary dryer was operated cocurrently. The experimental work was carried out to measure particle size distribution parameter of particle and the simulation work was carried out by developing mathematical model of drying process in rotary dryer by considering non-uniform particle size.

The particle size distribution was measured using a set of screens with size: $20,30,35,40,45,50,60,70$, and 80 mesh or $841,600,500,425,355,300,250,212,180$, and $150 \mu \mathrm{m}$ to obtain mass fraction of solid particles with mean diameter of $720.5,550,462.5,390,327.5$, $275,231,196,165 \mu \mathrm{m}$. The measurement results were analyzed using Rosin-Rammler and Gamma distribution model to determine the model parameters. RosinRammler and Gamma distribution model can be represented in Equation (1) and (2) respectively.

$$
\begin{aligned}
& p\left(D_{p}\right)=\frac{n}{\bar{D}_{p}^{n}} D_{p}^{n-1} \exp \left[-\left(\frac{D_{p}}{D_{p}}\right)^{n}\right] \\
& p\left(D_{p}\right)=\frac{1}{\beta^{\alpha} \Gamma(\alpha)} D_{p}^{\alpha-1} \exp \left(-\frac{D_{p}}{\beta}\right)
\end{aligned}
$$

The value of Rosin-Rammler parameter, n, called spread parameter, was determined using the following exponential relation between particle diameter $D_{p}$, and mass fraction of particle with diameter greater than $D_{p}$, that is $\mathrm{M}_{\mathrm{D}}$

$M_{D}=\exp \left(-\left(\frac{D_{p}}{\overline{D_{p}}}\right)^{n}\right)$

where $\overline{\mathrm{D}}_{\mathrm{p}}$ is mean diameter and $\mathrm{n}$ is spread parameter.

The value of Gamma distribution parameters, $\alpha$ and $\beta$, was determined using Equation (4) and (5).

$\alpha=\left(\frac{\mu}{\sigma}\right)^{2}$ $\beta=\frac{\sigma^{2}}{\mu}$

The spreadness of distribution of both model can be measured using parameter coefficient of variance $(\mathrm{CV})$ defined as fllows,

$C V=\frac{\sigma}{\mu}$

The mathematical model of drying process in rotary dryer with non-uniform particle sizes was developed by combining the uniform particle size drying process model with particle size distribution models: RosinRammler and Gamma distribution model where coefficient of variation $(\mathrm{CV})$ becomes an important parameter.

Uniform particle size drying process model was developed by assuming steady state condition, plug flow with axial dispersion pattern for solid flow, uniform drying air condition throughout the dryer. The model consist of differential mass balance of moisture in solid particle in the rotary dryer that can be represented in Equation (7).

$-\frac{\partial X}{\partial \xi}+\frac{1}{P_{e}} \frac{\partial^{2} X}{\partial \xi^{2}}=\phi_{1}$

where,

$\xi=\frac{z}{L}, \phi_{1}=\frac{L R_{w}}{u}, P_{e}=\frac{L u}{D_{z}}$

The boundary conditions for Equation (7) are shown in Equation (9) and (10).

BC 1: $\xi=0, \quad \mathrm{X}=\mathrm{X}_{0}$

BC 2: $\xi=1, \quad \mathrm{dX} / \mathrm{d} \xi=0$

The Peclet number, or the inverse of axial dispersion number, in Equation (8) was determined using an empirical correlation by Liang Tseng Fan (1961) shown in Equation (11) and (12).

$\frac{\mathrm{D}_{\mathrm{z}}}{\mathrm{uL}}=\left(2.46 \times 10^{-12}\right)\left(\frac{\mathrm{F}}{\mathrm{DiSN}}\right)^{-202}, \frac{\mathrm{F}}{\mathrm{DiSN}}<0.287$

$\frac{\mathrm{D}_{\mathrm{z}}}{\mathrm{uL}}=\left(1.79 \times 10^{-10}\right)\left(\frac{\mathrm{F}}{\mathrm{DiSN}}\right)^{1.415}, \frac{\mathrm{F}}{\mathrm{DiSN}}>0.287$

Where the linear solid velocity, u, was obtained as follows,

$u=\frac{L}{t}$

Solids residence time in the rotary dryer $(\underline{t})$ was estimated from the empirical correlation [20], shown in Equation (14)

$\underline{t}=\frac{0.3464 L}{S N^{0.9} D i}-0.5904 \frac{L G}{F_{s}{ }^{\prime} D_{p}^{0.5}}$

The mathematical model of drying process in rotary dryer with non-uniform particle sizes was developed by combining the uniform particle size drying process model with particle size distribution models.

Rosin-Rammler and Gamma distribution model where coeffcient of variation (CV) becomes an important parameter.

Uniform particle size drying process model was developed by assuming steady state condition, plug flow with axial dispersion pattern for solid flow, uniform drying air condition throughout the dryer. The model consist of differential mass balance of moisture in solid particle in the rotary dryer that can be represented in Equation (7). 
$\frac{\partial X}{\partial t}=\frac{D_{e f f}}{r^{2}} \frac{\partial}{\partial r}\left(r^{2} \frac{\partial X}{\partial r}\right)$

with the following initial condition and boundary conditions,

$\mathrm{IC}: \mathrm{t}=0, \mathrm{X}(\mathrm{r}, 0)=\mathrm{X}_{0}$

$\mathrm{BC} 1: \mathrm{r}=0, \frac{\partial X}{\partial r}=0$

$\mathrm{BC} 2: \mathrm{r}=\mathrm{R}, \frac{\partial X}{\partial r}=-\frac{k_{G}\left(P_{A}^{s a t}-P_{A}\right) \beta^{\prime}}{\rho_{s} D_{e f f}}$

Parameter $\beta$ in Equation (18) is called partition factor defined in Equation (19) to account for surface resistance of mass transfer while gas side mass transfer coefficient in Equation (18) was estimated using empirical correlation [7].

$$
\beta=e^{-\left(\frac{x_{0}-x}{x_{0}}\right)}
$$

The partial differential equation reprsented in Equation (15) with initial and boundary conditions represented in Equation (16), (17) and (18) were discritized using implicit finite difference method with Crank Nicholson scheme to obtain a set of linear algebraic equations solved by matrix inversion method. The solution represents the values of solid moisture content at various position in the particle and at any instant. Then, the average moisture content of the solid at any instant can be obtained by the following equation,

$$
\bar{X}(t)=\frac{3}{R^{3}} \int_{0}^{R} X r^{2} d r
$$

The predicted result of $\bar{X}(t)$ was fitted into a simple exponential model,

$$
\bar{X}(t)=K e^{-B t}
$$

where the value of constants $\mathrm{K}$ and $\mathrm{B}$ can be obtained using least square method. Finally rate of drying per unit mass of dry solid can be obtained as follows,

$R_{w}=-\frac{d \bar{X}}{d t}=-K B e^{-B t}=B \bar{X}$

Differential Equation (6) with boundary conditions (8) and (9) was solved analytically to obtain moisture content of solid particle as a function of axial position in the rotary dryer and particle diameter, $\bar{X}\left(D_{p}, z\right)$.

The result of analytical solution was coupled with particle size distribution model to obtain the average moisture content in solid particle as a function of axialposition in the dryer $(\bar{X}(z))$ expressed in Equation (23).

$$
\overline{X_{\text {avg }}}(\xi)=\int_{0}^{\infty} p\left(D_{p}\right) \bar{X}\left(D_{p}, \xi\right) d D_{p}
$$

\section{RESULTS AND DISCUSSIONS}

The most important information needed in mathematical model development of rotary dryer is rate of solid drying. Rate of drying of ammonium sulphate particles was obtained from Equation (22), where the value of B was obtained by fitting the predicted results, from Equation (20), with the simple exponential model, Equation (21). The value of B was determined for various drying conditions or for different value of air temperature, humidity and velocity shown in Table 1 . Then, the following correlation was obtained, using linear regression, torelante constant $\mathrm{B}$ with operating variable

$$
\begin{aligned}
& \mathrm{v},, \mathrm{T} \text { and } \mathrm{D}_{\mathrm{p}} . \\
& B=3.34368 \times 10^{-12} v^{0.75719} H^{-0.01773} T^{4.87650} D_{p}^{-1.27485}
\end{aligned}
$$

And the rate of drying was obtained by substitution $\mathrm{B}$ from Equation (24) into Equation (22) as follows,

$R w=3.34368 \times 10^{-12} \mathrm{v}^{0.75719} H^{-0.01773} T^{4.8765} D_{p}^{-1.27485} \frac{}{X}$

This study explored the effect of particle size nonuniformity, expressed as Coefficient of Variance, on rotary dryer performance using Rosin-Rammler and Gamma distribution. The particle size non-uniformity was measured using a set of screens. Table 2 shows the experimental results of particle size distribution measurement. The average particle diameter, standard deviation, coefficient of variance, Rosin-Rammler distribution parameter, and Gamma distribution prameter can be obtained using data from Table 2 as follows: $\mu=330.22$ $\mu \mathrm{m}, \sigma=144.36 \mu \mathrm{m}, \mathrm{CV}=0.437, \mathrm{n}=2.3, \alpha=5.24, \beta=$ 63.

The mathematical model was developed to account for the effect of particle size non-uniformity on rotary dryer performance. In this case, the drying process model in rotary dryer with uniform particle size $D_{p}$ was combined with the particle size distribution model. The drying process model with uniform particle size was obtained by solving analitycally Equation (6) with boundary conditions (8) and (9) as follows,

$\bar{X}=f\left(D_{p}, z\right)=X_{0}\left(1-\frac{\phi_{1}}{P_{e}} \exp \left(-P_{e}\right)\left[1-\exp \left(P_{e} \xi\right)\right]-\phi_{1} \xi\right)$

This solution gives moisture content in solid particlewith diameter Dp at axial position, $z$, in rotary dryer. While mass fraction of particles with diameter Dp in a group of particles with various sizes was represented with Rosin-Rammler model shown in Equation (1) and Gamma distribution model shown in Equation (2). Then, the average moisture content at axial position, $\mathrm{z}$, in rotary dryer can be obtained from Equation (23), where $f\left(D_{p}, z\right)$ was found from Equation (26).

The integration in Equation (23) was carried out numerically using Simpson rule, where the higher limit of integration was replaced with $\mathrm{D}_{\mathrm{p}, \max }$ obtained from Equation (27).

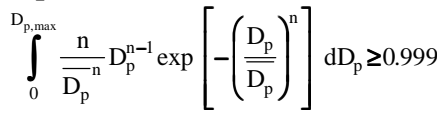

The simulation results are presented graphically in Fig. 1 and Fig. 2. Fig. 1 shows the average moisture content in solid at axial position in rotary dryer with Coefficient of Variance $(\mathrm{CV})$ as parameters. This figure depicts that for the value of $\mathrm{CV}$ less than 0.5, the non-uniformity of particle sizes does not give significant effect on the predicted moisture content profile and the predicted moisture content in soild particle effluent from rotary dryer. The effect of $\mathrm{CV}$ on the rotary dryer performance is significant for the value of $\mathrm{CV}$ greater than 0.5 . The moisture content in the solid effluent decrease (or the performance of rotary dryer increase) with increasing the value of $\mathrm{CV}$. Increasing $\mathrm{CV}$ means that the mass fraction of particles with diameter is significantly less than or more than the average of diameter increase. Increasing the fraction of fine particle will increase the drying rate due to large surface area. This is the explanation why the dryer performance increases with increasing the value of CV. 
IPTEK, The Journal for Technology and Science, Vol. 21, No. 3, August 2010

TABLE 1.

THE EFFECT OF $\mathrm{v}, \mathrm{H}$, T AND DP ON THE VALUE OF B

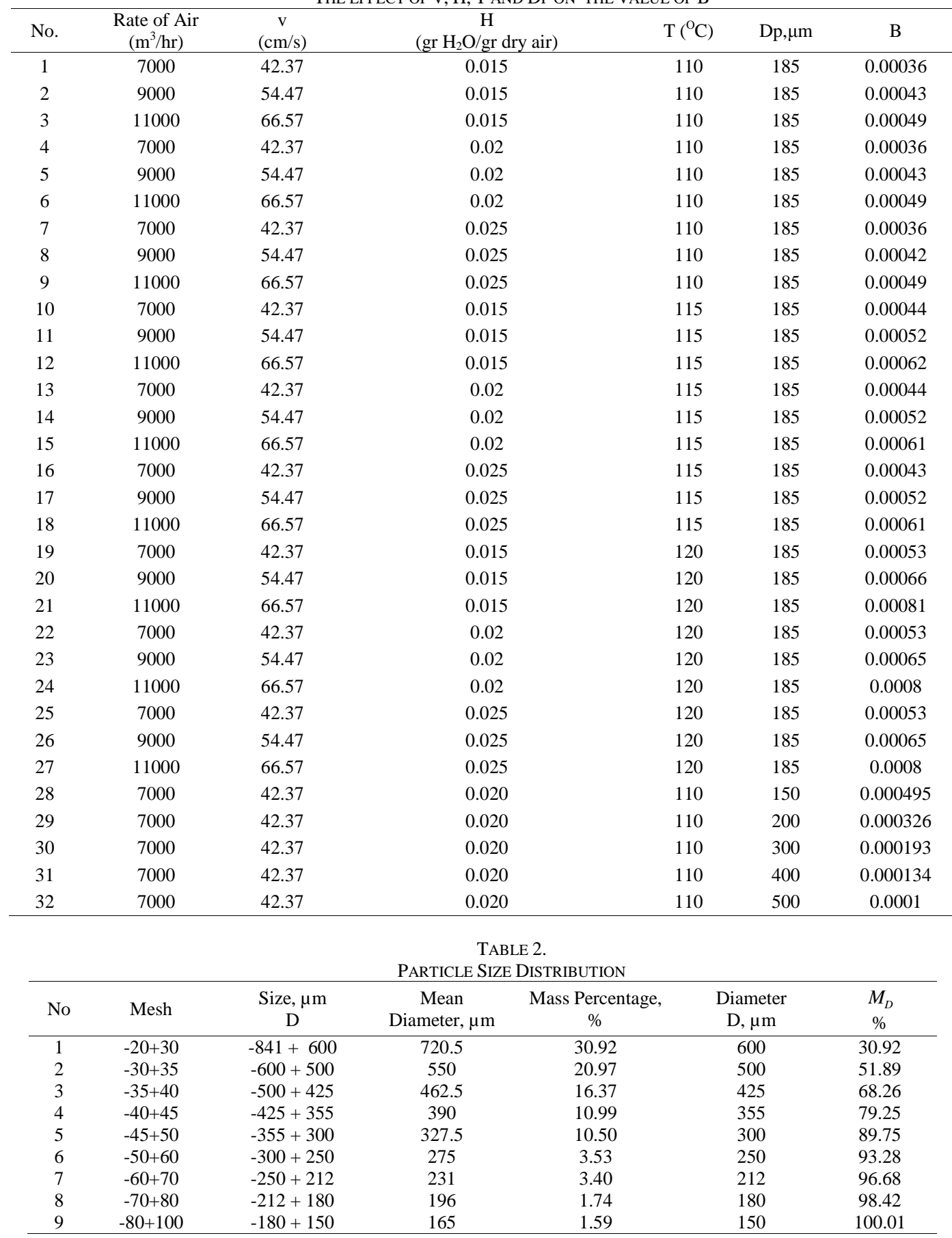

TABLE 3.

VALIDATION OF SIMULATION PREDICTIONS with A ROTARY DRYER OPERATING DATA IN PT.PETROKIMIA GRESIK

\begin{tabular}{|c|c|c|c|c|c|c|c|c|c|}
\hline \multirow{2}{*}{ No } & \multirow{2}{*}{$X(\%)$} & \multirow{2}{*}{$\mathrm{Ts}\left({ }^{\circ} \mathrm{C}\right)$} & \multirow{2}{*}{ Fs(ton/h) } & \multirow{2}{*}{$\operatorname{Tg}\left({ }^{\circ} \mathrm{C}\right)$} & \multicolumn{3}{|c|}{$\mathrm{X}$ out $(\%)$} & \multicolumn{2}{|c|}{ Error (\%) } \\
\hline & & & & & $\mathrm{RR}$ & GM & Pilot & RR & GM \\
\hline 1 & 0.615 & 70 & 36 & 114 & 0.05 & 0.06 & 0.045 & 11.11 & 33.33 \\
\hline 2 & 1.175 & 70 & 33 & 113 & 0.06 & 0.07 & 0.095 & 36.84 & 26.32 \\
\hline 3 & 0.985 & 70 & 30 & 117 & 0.05 & 0.06 & 0.075 & 33.33 & 20 \\
\hline 4 & 0.655 & 65 & 36 & 117 & 0.05 & 0.05 & 0.075 & 33.33 & 33.33 \\
\hline 5 & 0.675 & 70 & 33 & 115 & 0.05 & 0.06 & 0.075 & 33.33 & 20 \\
\hline
\end{tabular}


Fig. 2 shows the effect of the application of distribution model (Rosin-Rammler and Gamma distribution) on the solid misture content profile in the rotary dryer. The application of Rosin-Rammler distribution model gives the smaller prediction of solid moisture content in rotary dryer compared to the application of Gamma distribution model. This is due to the Rosin-Rammler model that gives higher prediction of small particle size mass fraction compared to the Gamma distribution model.

The prediction results either using Rosin-Rammler or Gamma distribution model was compared to rotary dryer operating data in PT Petrokimia Gresik and the comparison is shown in Table 3. The application of RosinRammler and Gamma distribution model give the prediction with average deviation of $29.6 \%$ and $26.6 \%$ (compared to the operating data) respectively based on the moisture content in the solid product.

\section{CONCLUSIONS}

This work has studied the effect of particle size distribution on rotary dryer performance and expressed as the profile of moisture content in solid along the dryer by assuming uniform condition of air along the dryer as the inlet condition. In this case, the moisture balance in the rotary dryer is coupled with particle size distribution model. The particle size distribution model considered is Rosin-Rammler and Gamma function model. Using Gamma function distribution, the study shows that for the value of the coefficient of varience less than 0.5 , particle size distribution does not have significant effect on dryer performance.

For the value of $\mathrm{CV}$ greater than 0.5 , the dryer performance increases (or outlet solid moisture content decrease) with increasing the value of $\mathrm{CV}$. The application of Rosin-Rammler model gives lower prediction of outlet solid moisture content compared to the application of Gamma function model. The deviation of product moisture content is predicted from the drying model with application of Rosin-Ramler and Gamma distribution was $29.6 \%$ and $26.6 \%$ respectively, but still acceptable by the industry.

\section{REFERENCES}

[1] E. K. Akpinar, I. Dincer, 2005, "Application of moisture transfer models to solid drying", Proceeding of the Institution of Mechanical Engineers, 219, A3.

[2] R. Caesaryanto, S. AlRasyid, Margono, K. Budikarjono, Susianto, A. Altway, 2009, "Eksperimen dan simulasi karakteristik pengeringan pupuk ammonium sulfat", Proceeding Seminar Aptecs.

[3] L. T. Fan, Ahn, and Yong-Kee, 1961, "Axial dispersion of solids flow systems", Applied Scientific Research, vol.10, no.1, pp. 465-470.

[4] N. J. Fernandes, C. H. Ataide, and M. A. S. Barrozo, 2009, "Modeling and experimental study of hydrodynamic and drying characteristics of an industrial rotary dryer", Brazilian Journal of Chemical Engineering, Volume 26, No 2, pp. 331-341
[5] S. J. Friedman, W. R. Jr. Marshall, 1949a, "Studies in rotary drying - Part 1. Hold up and dusting", Chem Eng Progress, vol.45, no. 8, pp. 482-493.

[6] S. J. Friedman, W. R. Jr. Marshall, 1949b," Studies in rotary drying - Part 2. Heat and mass Transfer", Chem Eng Progress, vol.45, no. 9 , pp. $573-588$

[7] C. J. Geankoplis, 2003, Transport Processes and Separation Process Principles (Including Unit Operations, $4^{\text {th }}$ ed., Pearson Prentice Hall.

[8] A. K. Haghi, F. Z. Angiz, 2007, "Heat and mass transfer in thermal drying of wool: a Theoretical Approach". The Proceeding of The 5th Asia-Pacific Drying Conference, vol.1.

[9] A. K. Haghi, 2001 , "Simultaneous moisture and heat transfer in porous system", Journal of Computational and Applied Mechanics, 2(2), 195-243.

[10] A. K. Haghi, 2003, "Diffusion of heat and moisture through textiles", Int. Journal of Applied Mechanics and Engineering, 8(2), 233-243

[11] J. J. Kelly, 1995, "Rotary drying" In: Mujumdar A S (ed), Handbook of Industrial Drying, Marcel Dekker, Inc., New York, vol.1, pp. 161-183.

[12] I. C. Kemp, 2004, "Comparison of particle motion correlation for cascading rotary dryers", Proceeding of the $14^{\text {th }}$ International drying symposium, Brazil, Vol.B, pp. 790-797.

[13] C. T. Kiranoudis, Z. B. Maroulis and Marinos-Kouris 1997,'Modeling and optimization of fluidized bed and rotary dryers", Drying Technology, pp. 735-763.

[14] Liang-Tseng F, Ahn, and Yong-Kee, 1961, "Axial dispersion of solids flow systems", Applied Scientific Research, Vol. 10, no.1, pp. 465-470.

[15] M. H. Lisboa, A. B. Alves, D. S. Vitorino, W. B. Delaiba, J. R D. Finzer, and M. A. S. Barrozo, 2002, "A study about particle motion in rotary dryers", $2^{\text {nd }}$ Mercosur Congress on Chemical Engineering.

[16] A. S. Mujumdar, and W. Zhonghua, 2007, "Thermal drying technologies: New developments and future R \& D potential", The Proceeding of The 5th Asia- Pacific Drying Conference, Vol. 1.

[17] N. V. Menshutina, H. Leuenberger, A. Y. Troyankin and M. N. Puchkov, 2007, "Mathematical modeling as approach to design of drying process", The Proceeding of The 5th Asia-Pacific Drying Conference, Vol. 2.

[18] J. P. Pan, T. J. Wang, J. J. Yao and Y. Jin, 2006, "Granule transport and mean residence time in horizontal drum with inclined flights", Powder Technology, 16, pp. 50 - 58.

[19] R. F. Pacheco, and S. S. Stella, 1998, "Calculating capacity trend in rotary dryer", Brazilian Journal of Chemical Engineering, Vol 15, No 3.

[20] R. H. Perry, and C. H. Chilton, 1973, Perry's Chemical Engineers Handbook, $5^{\text {th }}$ ed., McGraw-Hill

[21] H. Purutyan, J. W. Carson, and T. G. Troxel, 2004, "Improve solids handling during thermal drying" Chemical Engineering Progress, 100, 11

[22] F. R. Schofield, and P. G. Glikin, 1962, "Rotary dryers and coolers for granular fertilizers", Trans. I Chem.E. Vol. 40, pp. 183-190.

[23] C. Strumillo, and T. Kudra, 1986, Drying: Principles, Applications and Design, Gordon and Breach Science Publishers, Montreaux, pp. 71.

[24] N. C. Tsourveloudis, and L. Kiralakis, 2003, "Rotary drying of olive stones Fuzzy modeling and controle", University Campus, Chania GREECE, \{nikost,kyralakis\}@dpem.tuc.gr

[25] F. Y. Wang, I.T. Cameron, J.D. Litster, and P.L. Douglas, 1993 "A Distributed parameter approach to the dynamics of rotary drying processes", Drying Technolog, Vol. 11, no. 7, pp. 16411656.

[26] L. Yliniemi, 1999, "Advanced control of a rotary dryer', $P h D$ Thesis, Department of Process Engineering, University of Oulu, Finland. 
IPTEK, The Journal for Technology and Science, Vol. 21, No. 3, August 2010

\begin{tabular}{|c|c|c|}
\hline \multicolumn{2}{|c|}{ Notation } & \multirow[t]{2}{*}{ Unit } \\
\hline B & $=$ Constant in Equation (21) & \\
\hline $\mathrm{CV}$ & $=$ Coefficient of Variance & - \\
\hline $\mathrm{D}_{\mathrm{z}}$ & $=\quad$ Axial dispersion coefficient & $\mathrm{m}^{2} \mathrm{~s}^{-1}$ \\
\hline$D_{\text {eff }}$ & $=$ Effective diffusivity of moisture in solid particle & $\mathrm{m}^{2} \mathrm{~s}^{-1}$ \\
\hline Di & $=$ Rotary dryer diameter & $\mathrm{m}$ \\
\hline$D_{p}$ & $=$ Particle diameter & $\mathrm{m}$ \\
\hline$\frac{p}{D_{p}}$ & $=$ Average particle diameter & $\mathrm{m}$ \\
\hline$D_{p, \max }$ & $=$ Maximum particle diameter & $\mathrm{m}$ \\
\hline $\mathrm{F}$ & $=$ Solid volumetric rate per drum cross sectional area & $\mathrm{m} \mathrm{s}^{-1}$ \\
\hline$F_{s}{ }^{\prime}$ & $=$ Dried solid mass velocity in axial direction & $\mathrm{kg} \mathrm{m}^{-2} \mathrm{~s}^{-1}$ \\
\hline $\mathrm{F}_{\mathrm{s}}$ & $=$ Solid flow rate & ton $/ \mathrm{h}$ \\
\hline G & $=$ Air mass velocity per cross-sectional area of RD & $\mathrm{kg} \mathrm{m}^{-2} \mathrm{~s}^{-1}$ \\
\hline $\mathrm{H}$ & $=$ Air humidity & - \\
\hline $\mathrm{K}$ & $=$ Constant in Equation (21) & \\
\hline $\mathrm{k}_{\mathrm{G}}$ & $=$ Gas side mass transfer coefficient & \\
\hline $\mathrm{L}$ & $=\quad$ Length of dryer & $\mathrm{m}$ \\
\hline$M_{D}$ & $=$ Fraction of particles with diameter greater than $D_{p}$ & \\
\hline $\mathrm{n}$ & $=$ Rosin-Rammler parameter & \\
\hline $\mathrm{N}$ & $=$ Rotation speed of rotary dryer & $\mathrm{s}^{-1}$ \\
\hline$p\left(D_{p}\right)$ & $=\quad$ Particle size density function & \\
\hline $\mathrm{P}_{\mathrm{A}}$ & $=$ Partial pressure of water vapour in air & $\mathrm{Pa}$ \\
\hline$P_{A}^{\text {sat }}$ & $=$ Saturated vapor pressure of water & $\mathrm{Pa}$ \\
\hline $\mathrm{P}_{\mathrm{e}}$ & $=$ Peclet Number & - \\
\hline $\mathrm{r}$ & $=$ Radial position in solid particle & - \\
\hline $\mathrm{R}$ & $=$ Particle radius & - \\
\hline $\mathrm{R}_{\mathrm{w}}$ & $=$ Drying rate per unit mass of dry solid & $\mathrm{s}^{-1}$ \\
\hline $\mathrm{S}$ & $=$ Slope of the drum & $\square$ \\
\hline $\mathrm{t}$ & $=$ Time & $\mathrm{s}$ \\
\hline$\underline{\mathrm{t}}$ & $=$ Residence time of solid in drum & $\mathrm{s}$ \\
\hline $\bar{T}$ & $=$ Temperature & $\mathrm{K}$ \\
\hline $\mathrm{T}_{\mathrm{g}}$ & $=$ Gas temperature & K \\
\hline $\mathrm{T}_{\mathrm{s}}^{\circ}$ & $=$ Solid temperatur & $\mathrm{K}$ \\
\hline u & $=\quad$ Linear velocity of solid in the drum & $\mathrm{m} \mathrm{s}^{-1}$ \\
\hline $\mathrm{X}$ & $=$ Local moisture content in solid particle & - \\
\hline $\bar{X}$ & $=$ Average moisture content in solid particle & - \\
\hline $\bar{X}_{\text {avg }}$ & $=$ Average moisture content in a group of solid with various diameter & - \\
\hline $\mathrm{z}$ & Axial position in rotary dryer & $\mathrm{m}$ \\
\hline \multicolumn{3}{|c|}{ Greeks symbols } \\
\hline$\alpha$ & $=$ Parameter of Gamma distribution & - \\
\hline$\beta$ & $=$ Parameter of Gamma distribution & - \\
\hline$\beta$, & $=$ Partition coefficient & - \\
\hline$\phi_{1}$ & $=$ Defined in Equation $(8)$ & - \\
\hline$\mu$ & $=$ Mean diameter of solid particle & $\mathrm{m}$ \\
\hline$\xi$ & $=$ Dimensionless axial position in rotary dryer & - \\
\hline$\rho_{\mathrm{s}}$ & $=$ Density of solid particle & $\mathrm{kg} \mathrm{m}^{-3}$ \\
\hline$\sigma$ & $=$ Standard deviation of particle diameter & $\mathrm{m}$ \\
\hline
\end{tabular}

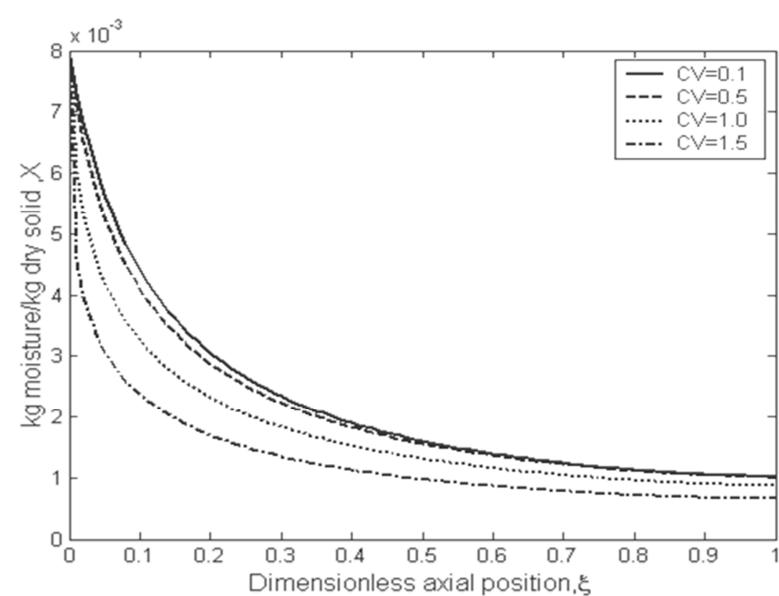

Fig. 1.The effect of particle size distribution on the profile of solid moisture content in rotary dryer using Gamma function distribution model.

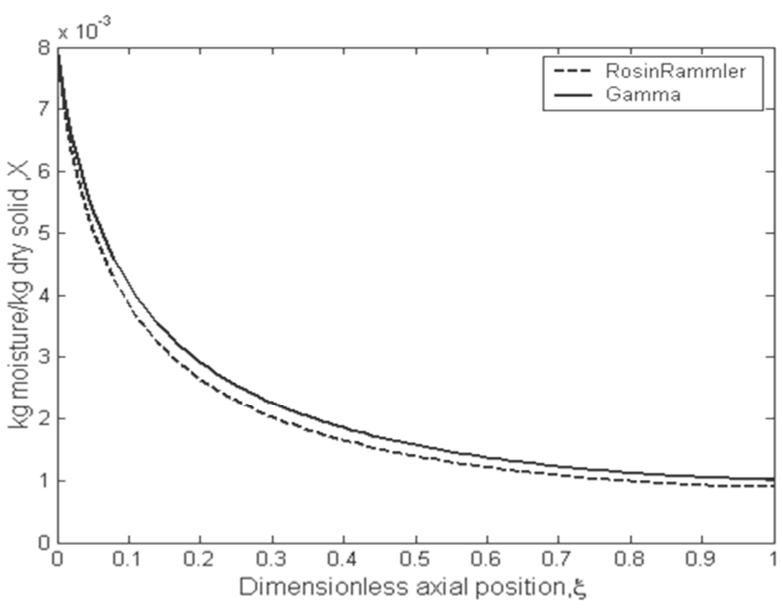

Fig. 2. The effect of distribution model (Rosin-Rammler and Gamma distribution) application on the profile of solid moisture content in rotary dryer. $\mu=330.22 \mu \mathrm{m}, \mathrm{CV}=0.437$. 
IPTEK, The Journal for Technology and Science, Vol. 21, No. 3, August 2010 